\title{
Gross Total Resection of a Recurrent Cavernous Sinus Meningioma through a Combined Transzygomatic Transcavernous and Extended Middle Fossa Approach with Cavernous Carotid Denudation
}

\author{
Yoichi Nonaka ${ }^{1}$ Naokazu Hayashi ${ }^{1}$ Takanori Fukushima ${ }^{2,3}$ \\ ${ }^{1}$ Department of Neurosurgery, Tokai University School of Medicine, \\ Kanagawa, Japan \\ 2 Division of Neurosurgery, Duke University Medical Center, Durham, \\ North Carolina, United States \\ ${ }^{3}$ Carolina Neuroscience Institute, Raleigh, North Carolina, \\ Address for correspondence Yoichi Nonaka, MD, PhD, Department of \\ Neurosurgery, Tokai University School of Medicine, 143 Shimokasuya, \\ Isehara, Kanagawa 259-1193, Japan \\ (e-mail: ynonaka1971@yahoo.co.jp).
} United States

J Neurol Surg B Skull Base 2022;83(suppl S3):e627-e629.

\begin{abstract}
Keywords

- cavernous meningioma

- middle fossa approach

- transcavernous approach

- transzygomatic approach

Objective The aim of this study is to describe surgical management of invasive cavernous sinus meningioma with a combination of skull base approaches.

Design This study is an operative video.

Results Resection of the recurrent skull base meningioma is still challenging, especially if the tumor involves or encases the carotid artery. In this video, we describe our experience with the successful treatment of a recurrent skull base meningioma, which involved the entire cavernous sinus and the internal carotid artery. A 53-year-old male presented with a 1-year history of progressing right-side complete oculomotor palsy and facial dysesthesia. The patient had previously undergone craniotomy for the right-side petroclival cavernous meningioma (-Fig. 1A and $\mathbf{B}$ ). Total 8 years after the first surgery, the remaining portion of the cavernous sinus grew up and extended into the posterior fossa (-Fig. 1C). Then the second surgery was performed to resect only the posterior fossa component (-Fig. 1D). However, the follow-up magnetic resonance imaging revealed an aggressive tumor regrowth in 2 years. The tumor occupied the right middle fossa with an extension to the posterior fossa and infratemporal fossa
\end{abstract}

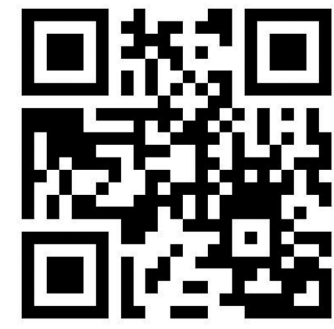

received

April 1, 2020

accepted

November 3, 2020

published online

May 3, 2021

www.thieme.com/skullbasevideos

www.thieme.com/jnlsbvideos

DOI https://doi.org/ 10.1055/s-0041-1727147. ISSN 2193-6331. (c) 2021. The Author(s).

This is an open access article published by Thieme under the terms of the Creative Commons Attribution-NonDerivative-NonCommercial-License, permitting copying and reproduction so long as the original work is given appropriate credit. Contents may not be used for commercial purposes, or adapted, remixed, transformed or built upon. (https://creativecommons.org/ licenses/by-nc-nd/4.0/)

Georg Thieme Verlag KG, Rüdigerstraße 14, 70469 Stuttgart, Germany 


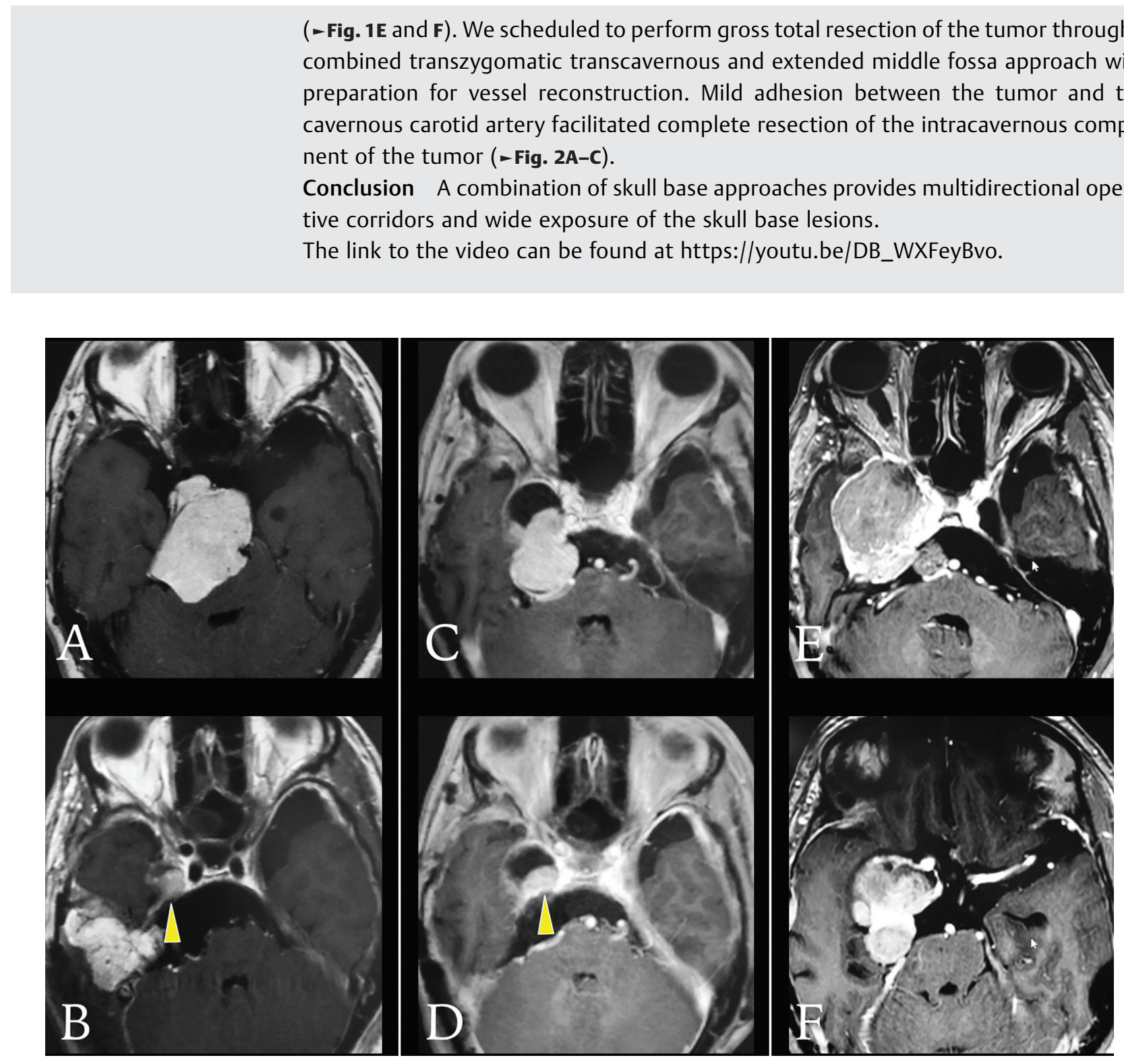

Fig. 1 Pre-and postoperative MRI. (A) Preoperative postcontrast MRI of the first surgery demonstrates a right-sided large cavernous-petroclival meningioma with severe compression of the brainstem. (B) Postoperative MRI of the first surgery demonstrates a small residual tumor at the right cavernous sinus (yellow arrowhead). (C) Preoperative MRI of the second surgery demonstrates tumor regrowth of the residual cavernous portion with extension to the right posterior fossa. (D) Postoperative MRI of the second surgery demonstrates a residual tumor at the right cavernous sinus (yellow arrowhead) (E), (F) preoperative MRIs of the third surgery demonstrate aggressive tumor regrowth. A large tumor occupies the right middle fossa with multidirectional extension with engulfment of the right cavernous carotid artery. MRI, magnetic resonance imaging. 


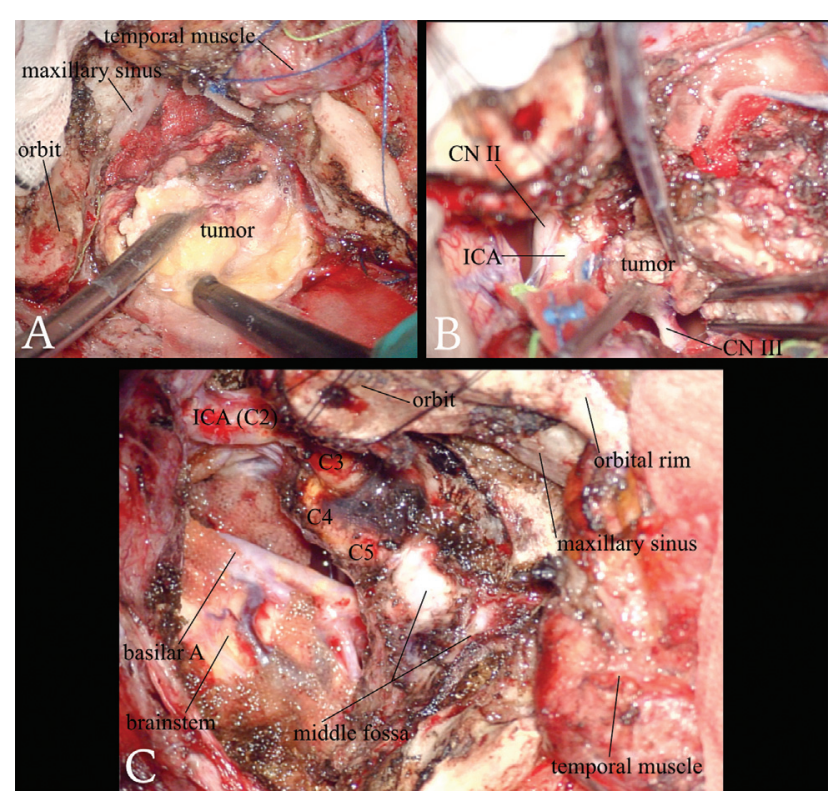

Fig. 2 Intraoperative still images. (A) Resection of the right middle fossa component of the tumor using an ultrasonic aspirator. (B) The right oculomotor nerve is involved entirely by the tumor. (C) Final view of the gross total resection of the tumor through a transzygomatic-transcavernous and extended middle fossa approach. The cavernous segment of the right carotid artery is denuded with the removal of the intracavernous component of the tumor. The lateral aspect of the brainstem is well exposed.

\section{Funding \\ None.}

Conflict of Interest

None declared. 